\title{
O PROCESSO DE APRENDIZAGEM INDIVIDUAL A PARTIR DO ERRO VIVENCIADO POR GESTORES DE EMPRESAS DE BASE TECNOLÓGICA
}

\author{
THE INDIVIDUAL LEARNING PROCESS ARISING FROM \\ ERRORS COMMITTED BY MANAGERS IN NEW \\ TECHNOLOGY-BASED FIRMS
}

\section{EL PROCESO DE APRENDIZAJE INDVIDUAL DEL ERROR EXPERIMENTADO POR LOS GERENTES DE EMPRESAS DE BASE TECNOLÓGICA}

\author{
Henrique Geraldo Rodrigues \\ Docente da Universidade Federal de Uberlândia, \\ Brasil \\ Doutor em Administração de Empresas pela \\ Universidade Presbiteriana Mackenzie, Brasil \\ henrique@ufu.br

\section{Diógenes de Souza Bido} \\ Docente da Universidade Presbiteriana \\ Mackenzie, Brasil \\ Doutor em Administração pela Universidade de \\ São Paulo, Brasil \\ diogenesbido@yahoo.com.br
}

\author{
Contextus \\ ISSNe 2178-9258 \\ Organização: Comitê Científico Interinstitucional \\ Editor-Chefe: Diego de Queiroz Machado \\ Avaliação: double blind review pelo SEER/OJS \\ Artigo indicado para fast-track no XXII Seminários em \\ Administração (SEMEAD 2019) \\ Recebido em 19/11/2019 \\ Aceito em 22/11/2019 \\ http://dx.doi.org/10.19094/contextus.v17i3.42748
}

\section{RESUMO}

O objetivo, neste artigo, foi identificar e analisar, no contexto de empresas de base tecnológica, o processo por meio do qual o erro individual foi abordado e levou à aprendizagem a partir de sua ocorrência. Mediante um estudo qualitativo básico, entrevistaram-se nove gestores de empresas de base tecnológica sediadas no Brasil. Os principais resultados indicam que a análise das situações-problema em que os efeitos dos erros se manifestam constituem-se em um importante estágio do processo de detecção e correção do erro. Também, delineou-se um percurso processual para a aprendizagem individual a partir do erro, no trabalho, pelo qual se evidencia como os estágios de detecção e correção do erro articulam-se com elementos que influenciam positivamente a aprendizagem. Tal perspectiva implica que as abordagens ao fenômeno devem considerar que a efetividade da aprendizagem a partir do erro é dependente do envolvimento do indivíduo no tratamento do erro.

Palavras-chave: aprendizagem a partir do erro; erro individual; processo de aprendizagem individual a partir do erro; empresas de base tecnológica.

\begin{abstract}
The purpose behind this article was to identify and analyse, in the context of technology-based firms, the process by which individual error was addressed and how its occurrence led to learning. Through a basic qualitative research study, nine managers were interviewed from Brazilian-based technology firms. The main results indicate that the situation-problem, in which the effects of errors are manifest, is established upon an important stage for error detection and correction. Also, a procedural path was outlined for individual learning from errors at work, which shows how the stages of error detection and correction articulate with elements that positively influence learning. Such perspectives imply that approaches to the phenomenon should consider that the effectiveness of learning from errors is dependent upon individual involvement in treating the problem.
\end{abstract}

Keywords: learning from errors; individual error; individual learning process from error; technology-based firms. 


\section{O PROCESSO DE APRENDIZAGEM INDIVIDUAL A PARTIR DO ERRO VIVENCIADO POR GESTORES DE EMPRESAS DE BASE TECNOLÓGICA}

\section{RESUMEN}

El objetivo de este artículo fue identificar y analizar, en el contexto de las empresas de base tecnológica, el proceso mediante el cual se abordó el error individual y se logró aprendizajes a partir de su ocurrencia. A través de un estudio cualitativo básico, se entrevistaron a nueve gerentes de empresas de base tecnológica con sede en Brasil. Los resultados principales indican que las situaciones problemáticas, donde se manifiestan los efectos de los errores, constituyen una etapa importante para detección y corrección de errores. Además, se describió una ruta de procedimiento para aprender individualmente, a partir del error en el trabajo, por lo cual se evidencia como las etapas de detección y corrección del error se articulan con elementos que influyen positivamente en el aprendizaje. Tal perspectiva implica en que los enfoques al fenómeno deben considerar que la efectividad del aprendizaje a partir del error depende de la participación del individuo en el tratamiento del error.

Palabras clave: aprendizaje del error; error individual; proceso de aprendizaje individual del error; empresas de base tecnológica.

\section{INTRODUÇÃO}

Como um componente da ação humana, assume-se que não é possível evitar, por completo, os erros, inclusive, nas organizações, onde a tentativa de prevenir - ou, mesmo, erradicar - a sua ocorrência pode mostrar-se inútil (RYBOWIAK et al.,1999; VAN DYCK et al., 2005; ZHAO; OLIVERA, 2006; FRESE; KEITH, 2015). Investigações do campo de estudos em administração e organizações têm dado enfoque ao tema, no entanto, por meio de abordagens que realçam diferentes aspectos da aprendizagem individual a partir dos erros, tais como os efeitos das emoções negativas sobre a motivação para aprender a partir do erro (ZHAO, 2011) e o aprendizado a partir dos erros de outras pessoas (KC; STAATS; GINO, 2013).

Por outro lado, a compreensão processual da aprendizagem individual a partir do erro, no contexto de trabalho, representa uma lacuna nos estudos sobre a aprendizagem individual e nas organizações, uma vez que se reconhece que a abrangência e a efetividade da aprendizagem a partir do erro são decorrentes da possibilidade de recuperação de informações e eventos relacionados ao processo do erro (LOVE; JOSEPHSON, 2004). Tal ângulo tem sido sugerido em recentes revisões da literatura, que apontam as oportunidades de expansão da compreensão sobre o fenômeno por meio de pesquisas que adotem lentes temporais - o antes, o durante e o pós-erro (GOODMAN et al., 2011; LEI et al. 2016),

Nessa perspectiva, esta pesquisa partiu do seguinte problema: como o erro individual é abordado, no ambiente de trabalho, e de que forma leva a aprendizagens? Observa-se que os ambientes de trabalho em que há maior tolerância à ocorrência de erros são aqueles cujos resultados são dependentes de processos de pesquisa e desenvolvimento, e de inovação (CANNON; EDMONDSON, 2001), nos quais, frequentemente, se lida com processos e tecnologias novos ou pouco estruturados, o que sujeita as pessoas a mais experimentação e erros (FRESE; KEITH, 2015). É o caso das empresas de base tecnológica, cujas operações baseiamse no desenvolvimento e comercialização de produtos ou processos tecnologicamente 
inovadores. Quando em seus estágios iniciais de desenvolvimento, tais organizações, normalmente, são expostas a diversos problemas decorrentes da escassez de recursos financeiros e gerenciais (LOCKETT; WRIGHT, 2005; PERUSSI FILHO; ESCRIVÃO FILHO, 2012), em decorrência do que a possibilidade de ocorrência de erros é maior.

Desse modo, ou seja, pelo entendimento de que esse contexto é marcado pela presença do erro humano, ao mesmo tempo que isto é visto como um elemento inerente ao processo de desenvolvimento dessas organizações, definiram-se, como campo da pesquisa, o ambiente de trabalho de empresas de base tecnológica em estágio inicial de desenvolvimento. Por meio desta pesquisa, objetivou-se, então, identificar e analisar, no contexto de empresas de base tecnológica, o processo por meio do qual o erro individual foi abordado e levou à aprendizagem a partir de sua ocorrência. Para isso, foram entrevistados nove gestores de empresas de base tecnológica sediadas no Brasil.

Em relação à organização do artigo, na sequência, no referencial teórico, define-se o erro individual e, depois, discutem-se a abordagem ao erro e a aprendizagem a partir do erro. Posteriormente, é apresentada a metodologia, além do perfil dos nove gestores entrevistados e da caracterização das empresas. Na sequência, são feitas a apresentação, análise e discussão dos dados, com base nas categorias temáticas identificas pela análise dos dados. Por fim, fazemse as considerações finais.

\section{REFERENCIAL TEÓRICO}

\subsection{Definição de erro em seu nível individual}

Na literatura sobre aprendizagem a partir dos erros no local de trabalho, são encontrados estudos relacionados aos três níveis de análise do fenômeno, quais sejam o individual, o grupal e o organizacional (ou nível do sistema). Neste trabalho, o enfoque voltou-se à discussão do erro em seu nível individual e, nessa linha, o Quadro 1 traz definições de erro no nível do indivíduo ou aplicáveis, também, a este nível, quando os autores não delimitaram a definição, especificamente, aos níveis grupal ou organizacional.

Observa-se a compreensão segundo a qual o erro representa uma ação cujo resultado é discrepante do previsto, quase sempre, avaliado como negativo. O parâmetro levado em conta para a determinação de que ocorreu um desvio do resultado esperado pode ser uma meta (BAUER; MULDER, 2007; VAN DYCK et al. 2005); padrões, regras ou procedimentos 
(GOODMAN et al., 2011; LEI et al., 2016); planos e projetos experimentais ou inovadores (CANNON; EDMONDSON, 2001, p. 162; FRESE; KEITH, 2015). Especificamente, Cannon e Edmondson (2001), consideram que os erros podem ser resultantes, também, de falhas no âmbito do relacionamento interpessoal, expressadas na forma de interpretações equivocadas e conflitos interpessoais.

Quadro 1 - Definições de erro aplicáveis ao nível do indivíduo

\begin{tabular}{|c|c|}
\hline Autores & Definição de erro \\
\hline Ohlsson (1996, p. 242) & $\begin{array}{l}\text { O termo erro [...] refere-se a ações inadequadas cometidas durante a execução de } \\
\text { uma tarefa. }\end{array}$ \\
\hline $\begin{array}{l}\text { Cannon e Edmondson } \\
(2001, \text { p. } 162)\end{array}$ & $\begin{array}{l}\text { Nós conceituamos falha como desvio dos resultados esperados e desejados. Isto } \\
\text { inclui erros evitáveis e resultados negativos inevitáveis de experimentos e riscos. } \\
\text { Também, engloba falhas interpessoais, como mal-entendidos e conflitos. }\end{array}$ \\
\hline $\begin{array}{l}\text { Love e Josephson } \\
(2004, \text { p. } 71)\end{array}$ & $\begin{array}{l}\text { [...] erro é definido como um "desvio do que é almejado e causado por ações } \\
\text { humanas". }\end{array}$ \\
\hline $\begin{array}{l}\text { van Dyck et al. (2005, } \\
\text { p. } 430)\end{array}$ & $\begin{array}{l}\text { Erros podem ser definidos como desvios não intencionais de metas ou padrões [...]. } \\
\text { De acordo com esta definição, os erros implicam uma discrepância não intencional } \\
\text { entre o estado atual e o desejado }\end{array}$ \\
\hline $\begin{array}{l}\text { Zhao e Olivera }(2006 \\
\text { p. 1013) }\end{array}$ & $\begin{array}{l}\text { [...] nós definimos os erros como decisões e comportamentos individuais que (1) } \\
\text { resultam em uma lacuna indesejável entre um estado esperado e real e (2) podem } \\
\text { levar a consequências negativas reais ou potenciais para o funcionamento } \\
\text { organizacional, que poderiam ter sido evitadas. }\end{array}$ \\
\hline $\begin{array}{l}\text { Bauer e Mulder (2007, } \\
\text { p. 123) }\end{array}$ & $\begin{array}{l}\text { [...] uma ação individual é chamada de erro, se for executada de forma que uma } \\
\text { meta não seja alcançada e o alcance de objetivos de ordem superior seja ameaçado. }\end{array}$ \\
\hline $\begin{array}{l}\text { Goodman et al. (2011, } \\
\text { p. 152) }\end{array}$ & $\begin{array}{l}\text { "Erros" são, essencialmente, desvios não intencionais de regras ou procedimentos } \\
\text { [...] que podem resultar em resultados organizacionais adversos. }\end{array}$ \\
\hline $\begin{array}{l}\text { Frese e Keith }(2015, \mathrm{p} . \\
662)\end{array}$ & $\begin{array}{l}\text { [...] nós definimos erros de ação como desvios não intencionais de planos, metas ou } \\
\text { processos adequados de feedback, bem como ações incorretas resultantes da falta } \\
\text { de conhecimento. }\end{array}$ \\
\hline $\begin{array}{l}\text { Lei et al. }(2016, p . \\
1316)\end{array}$ & $\begin{array}{l}\text { Erros nas organizações são, essencialmente, desvios não intencionais e, } \\
\text { potencialmente, evitáveis de metas e padrões, especificados na organização, que } \\
\text { podem gerar consequências adversas ou positivas à organização. }\end{array}$ \\
\hline
\end{tabular}

Fonte: elaborado própria.

Uma característica relevante dos erros cometidos pelos indivíduos refere-se à não intencionalidade na geração desse tipo de evento (FRESE; KEITH, 2015; GOODMAN et al., 2011; LEI et al., 2016; VAN DYCK et al. 2005). Isto significa que quando o indivíduo, de forma deliberada, não cumpre uma regra ou age de modo diferente de normas e padrões exigidos à execução de seu trabalho, está cometendo uma violação e não um erro (FRESE; KEITH, 2015). Nessa linha, os erros podem ser vistos como situações evitáveis (ZHAO; OLIVERA, 2006) ou potencialmente evitáveis (LEI et al., 2016).

É interessante notar que, não necessariamente, os erros impactarão, de modo negativo, os resultados organizacionais. Em algumas situações, as consequências negativas dos erros podem mostrar-se são, apenas, potenciais (ZHAO; OLIVERA, 2006), ao passo que, em outras, os erros, de modo contrário, podem produzir consequências positivas para a organização (LEI et al., 2016). Nestas situações, igualmente, não se encontra a busca consciente pela geração de 
resultados superiores; o erro mantém sua característica de desvio não intencional do que era previsto de ser realizado ou alcançado.

O erro, essencialmente, é provocado pela ação humana (LOVE; JOSEPHSON, 2004) e, ainda que a delimitação entre as responsabilidades individual e coletiva pela ocorrência de um erro possa ser uma tarefa complexa, a classificação de um erro como sendo de nível individual requer que ele tenha sido decorrente de ação, comportamento ou decisão de, particularmente, um indivíduo (BAUER; MULDER, 2007; ZHAO; OLIVERA, 2006), “[...] sem a participação de outros indivíduos [...]" (LEI et al., 2016, p. 1316).

Na literatura, em inglês, sobre erros e aprendizagem no campo das organizações, podem ser encontrados diferentes termos pelos quais os autores referem-se ao fenômeno. Cannon e Edmondson (2001), por exemplo, utilizam-se, concomitantemente, dos termos falha (failure), e erro (error), inclusive, na definição dada ao conceito. Por sua vez, Dahlin et al. (2017) empregam tanto error quanto mistake para referirem-se a erro, normalmente, de forma conjunta - “[...] mistake and errors [...]” (p. 1) ou “[...] errors and mistakes [...]” (p. 2).

Embora alguns autores sugiram que, na literatura, os três termos sejam utilizados de forma intercambiável (BAUER; MULDER, 2007), observa-se, em pesquisas mais recentes (FRESE; KEITH, 2015; LEI et al., 2016), a preocupação com a distinção, especificadamente, entre falha e erro, e a tendência de consolidação do termo error na abordagem ao fenômeno da aprendizagem a partir dos erros. As falhas dizem respeito a resultados organizacionais negativos ou diferentes do esperado e, normalmente, são uma consequência de erros ou de uma combinação de fatores que inclui o erro tendo-se em conta que, não necessariamente, os erros terão como consequência uma falha (FRESE; KEITH, 2015; LEI et al., 2016).

\subsection{A abordagem ao erro e a aprendizagem a partir da sua ocorrência}

Os esforços praticados, nas organizações, para a promoção da aprendizagem a partir de erros, decorrem, basicamente, do propósito de prevenir que os mesmos erros sejam cometidos, no futuro (GOODMAN et al., 2011). Como evidenciado por meio do Quadro 2, definições de aprendizagem a partir dos erros tendem a contemplar tal perspectiva, expressa na forma de otimização do trabalho (RYBOWIAK et al., 1999), de melhoria do comportamento (BAUER; MULDER, 2007) ou de ações que bloqueiem a recorrência do erro (DAHLIN et al., 2017).

Para aprender algo com um erro cometido, é preciso, primeiro, tomar consciência do próprio erro; segundo, é necessário que a causa do erro seja identificada e passível de 
modificação (OHLSSON, 1996). Mediante o reconhecimento da ocorrência de um erro, o indivíduo tem condições para, na sequência, iniciar o processo de correção do erro, o que envolve refletir sobre e analisar a situação de erro, identificar as causas do erro, implementar as soluções requeridas e adotar novas formas de agir (BAUER; MULDER, 2007; ZHAO, 2011; DAHLIN et al., 2017).

Quadro 2 - Definições de aprendizagem a partir dos erros

\begin{tabular}{|l|l|}
\hline \multicolumn{1}{|c|}{ Autores } & \multicolumn{1}{c|}{ Definição de aprendizagem a partir dos erros } \\
\hline $\begin{array}{l}\text { Rybowiak et al. } \\
(1999, \text { p. 534) }\end{array}$ & $\begin{array}{l}\text { [...] 'aprendizagem a partir dos erros' refere-se a aprender algo para o futuro, para que } \\
\text { os planos de trabalho sejam otimizados a longo prazo. }\end{array}$ \\
\hline $\begin{array}{l}\text { Bauer e Mulder } \\
(2007, \text { p. 124) }\end{array}$ & $\begin{array}{l}\text { Aprendizagem a partir dos erros, no trabalho, pode ser considerada como uma } \\
\text { subcategoria da aprendizagem experiencial não formal, pois emprega a construção do } \\
\text { conhecimento de um evento episódico. Tal aprendizado pode ser representado como um } \\
\text { processo adaptativo fundamental que implica as etapas de (i) uma experiência concreta, } \\
\text { (ii) reflexão e análise, (iii) desenvolvimento de uma (nova) estratégia de ação, e (iv) } \\
\text { experimentação e avaliação da estratégia. }\end{array}$ \\
\hline Zhao (2011, p. 436) & $\begin{array}{l}\text { [..] nós definimos a aprendizagem a partir dos erros como o processo pelo qual os } \\
\text { indivíduos (a) refletem sobre os erros que produziram, (b) localizam as causas dos erros, } \\
\text { (c) desenvolvem conhecimento sobre as relações ação-resultado e os efeitos dessas } \\
\text { relações, no ambiente de trabalho, e (d) usar esse conhecimento para modificar ou } \\
\text { melhorar seu comportamento ou tomada de decisão. }\end{array}$ \\
\hline $\begin{array}{l}\text { Dahlin et al. (2017, } \\
\text { p. 6) }\end{array}$ & $\begin{array}{l}\text { Definimos a aprendizagem com erro e falha como o processo pelo qual indivíduos, } \\
\text { grupos ou organizações identificam eventos de erro ou falha, analisam esses eventos } \\
\text { para encontrar suas causas, e buscam e implementam soluções para evitar erros ou falhas } \\
\text { semelhantes, no futuro. }\end{array}$ \\
\hline
\end{tabular}

Fonte: elaboração própria.

Em estudos sobre gerenciamento do erro e aprendizagem a partir dos erros, o processo de abordagem ao erro é descrito por meio de diferentes etapas, as quais, contudo, apontam para certa similaridade dos elementos que as compõem. O processo de recuperação de erros proposto por Sasou e Reason (1999), é descrito por meio dos estágios detecção, indicação e correção; o modelo de reporte de erro, de Zhao e Olivera (2006), é estruturado em torno das fases detecção de erros, avaliação da situação e resposta comportamental; e o processo de gerenciamento de erro, de Frese e Keith (2015), é descrito pela perspectiva temporal, antes e após o erro.

Na discussão que se segue, adotou-se como parâmetro para a discussão dos elementos presentes nos processos de abordagem ao e de aprendizagem a partir dos erros, identificados por meio da revisão da literatura, a perspectiva de Ohlsson (1996), segundo a qual o processo de aprendizagem a partir dos erros é composto por duas funções cognitivas principais, detecção do erro e correção do erro, que, também, representam fases desse processo. 


\subsubsection{Detecção do erro}

A detecção de erros diz respeito ao reconhecimento, pelo próprio indivíduo, de que ele cometeu um erro, ainda que, nesse momento, as causas do erro não sejam compreendidas (ZHAO, 2011; FRESE; KEITH, 2015). A detecção do erro decorre da comparação do resultado obtido com aquele que se esperava alcançar (OHLSSON, 1996), o que pode ser feito pelo próprio responsável pelo erro ou por outras pessoas, internas ou externas à organização e que, de algum modo, estão envolvidas com a situação de erro (LOVE; JOSEPHSON, 2004). Com isso, os feedbacks emitidos por outras pessoas representam um mecanismo importante à identificação do erro e ao reconhecimento destes por quem o cometeu (CANNON; EDMONDSON, 2001).

Entretanto, as pessoas podem experimentar uma tensão psíquica associada ao erro, o que gera, além do temor de errar, reações emocionais negativas diante do erro cometido, como medo, constrangimento, estresse psíquico e raiva (RYBOWIAK et al., 1999). Nesse contexto, o indivíduo pode adotar comportamentos contraproducentes ao processo de abordagem ao erro. Com sua atenção voltada às próprias emoções, o indivíduo pode não agir de modo tempestivo na busca por soluções, contribuindo para que as consequências do erro persistam por mais tempo (FRESE; KEITH, 2015). Assim como, em vez de comunicar o erro, para lidar com a situação de modo efetivo, o indivíduo pode direcionar esforços para o encobri-lo, tirando de si a oportunidade de obter aprendizados com a situação (RYBOWIAK et al., 1999).

Zhao e Olivera (2006) mostram que o indivíduo, antes de reportar a ocorrência de um erro à sua chefia, tende a avaliar, de modo deliberado, os custos e benefícios potenciais, implicados no relato. Os motivos para não reportar a ocorrência do erro podem decorrer do temor de punições com reflexos financeiros (quem incluem a demissão), e de danos à sua imagem e reputação profissional, bem como do entendimento formulado sobre os possíveis custos econômicos e perdas para a reputação da organização. Em contrapartida, as razões levadas em conta para a comunicação do erro poderiam envolver a manutenção de seu autoconceito (reportar o erro seria coerente com a autoimagem), a redução de danos a potenciais vítimas, e a busca por aprendizado individual e para a organização (ZHAO; OLIVERA, 2006). Adicionalmente, Homsma et al. (2009) verificaram que o nível de gravidade percebido para as consequências do erro está associado à comunicação de sua ocorrência, de forma que, quanto maior a severidade dos danos, maior é a tendência de que erro seja reportado pelo indivíduo.

Rybowiak et al. (1999) propuseram a noção de que seja necessária uma competência individual para lidar com o erro, que diz respeito a, imediatamente à ocorrência do erro, saber 
como agir para corrigi-lo, o que representa, ante a falha, uma postura orientada à ação e a objetivos de curto prazo. Tal perspectiva aponta para o tempo que decorre entre a ocorrência e a abordagem ao erro, que é visto como um elemento crucial, tanto para proporcionar aprendizados efetivos quanto para reduzir os custos e consequências negativas decorrentes do erro (CANNON; EDMONDSON, 2001; FRESE; KEITH, 2015).

Apreende-se que a detecção do erro, bem como a forma pela qual a situação de erro é, inicialmente, avaliada, são determinantes à criação de contexto favorável à ocorrência do processo de aprendizagem a partir do erro, que transcorre à medida que o indivíduo busca a correção do erro, conforme discussão que se segue.

\subsubsection{Correção do erro}

A correção de um erro pode ser interpretada como a aquisição dos aprendizados necessários à melhoria da ação individual futura (OHLSSON, 1996). Tal ação envolve a análise e reflexão sobre a situação de erro, com a finalidade de identificar e compreender suas causas, desenvolver e implementar soluções que previnam a repetição do erro ou, se isto ocorrer, que reduzam suas consequências (BAUER; MULDER, 2007; ZHAO, 2011; DAHLIN et al., 2017).

O indivíduo pode aprender a partir de seus próprios erros tanto por meio da ajuda e do envolvimento de outras pessoas (EDMONDSON, 1996; CANNON; EDMONDSON, 2001; GHARAIBEH, 2012) quanto de forma autônoma, por meio da experimentação de formas alternativas de entender as relações entre seus comportamentos e resultados, configurando um “[...] aprendizado exploratório" (ZHAO, 2011, p. 437). Não obstante, independentemente do nível de participação de outras pessoas, compreende-se que a aprendizagem individual a partir do erro gera resultados mais efetivos e positivos se orientada por um processo de análise e experimentação reflexivas e sistemáticas (FRESE; KEITH, 2015), e não por tentativa e erro, ação que se mostra pouco estruturada e baseada em insuficiente conhecimento sobre a situação em que se originou o erro (VAN DER LINDEN et al., 2001).

Nessa perspectiva, a aprendizagem individual a partir do erro pode ser concebida como um tipo específico de aprendizagem experiencial, quase sempre não formal, que ocorre como uma reação ao feedback, ou seja, à detecção do erro, pelo próprio indivíduo ou por outrem (BAUER; MULDER, 2007). Desse modo, conforme as etapas do ciclo de aprendizagem experiencial (KOLB, 1984), após experienciar uma situação de erro, o indivíduo envolve-se em atividades de aprendizagem relativas à reflexão (que compreende a análise da causa do erro), 
ao desenvolvimento de novas estratégias de ação (que abrangem a apreciação de formas para alterar a causa e de alternativas para a ação futura, a alocação de informações e de recursos, e o planejamento da implementação da ação) e à implementação da nova estratégia (que engloba a experimentação e avaliação da nova estratégia) (BAUER; MULDER, 2007).

Por meio do conhecimento, análise e exploração das causas e medidas corretivas associadas a um erro, espera-se a aquisição de diferentes aprendizados pelo indivíduo, como a compreensão mais bem formulada sobre o processo e o sistema em que se deram o erro, a capacidade de prevenir a recorrência do erro e o entendimento sobre como lidar com situações de erro (FRESE; KEITH, 2015). Contudo, verifica-se que determinadas características, associadas à situação de erro, influenciam a aprendizagem. A avaliação de que as consequências do erro são graves e a percepção de que não é possível exercer controle pessoal sobre as causas do erro induzem tanto a geração de mais ideias para lidar com a causa do erro quanto a implementação de melhorias em maior extensão (HOMSMA et al., 2009). Quando as consequências do erro não são avaliadas como graves, as pessoas tendem a gerar menos soluções.

Diferentes atividades de aprendizagem são verificadas nos processos de correção de erros (BAUER; MULDER, 2007). Entre as não formais, identificam-se as interações com colegas e supervisores, a reflexão individual e a busca por atualização profissional de forma autorregulada (por exemplo, por meio de publicações profissionais); entre as formais, constatou-se a participação em treinamento e programas de desenvolvimento profissional. No âmbito das equipes de trabalho, do mesmo modo, apontam-se atividades informais e não estruturadas de aprendizagem que colaboram para o aprendizado individual, como as discussões e análise conjunta da situação de erro (CANNON; EDMONDSON, 2001; TJOSVOLD; YU; HUI, 2004), e as reuniões periódicas da equipe (PUTZ; SCHILLING; KLUGE; STANGENBERG, 2013).

\section{METODOLOGIA}

Nesta investigação, adotou-se como estratégia de pesquisa o estudo qualitativo básico, orientado à apreensão e interpretação de significados atribuídos a um determinado fenômeno, pelos sujeitos, na construção de sua realidade social (MERRIAM, 2009). Trata-se de uma estratégia que permite, no âmbito dos procedimentos metodológicos, o acesso aos dados por meio de uma única fonte, os quais são analisados com a finalidade de “[...] identificar padrões 


\section{O PROCESSO DE APRENDIZAGEM INDIVIDUAL A PARTIR DO ERRO VIVENCIADO POR GESTORES DE EMPRESAS DE BASE TECNOLÓGICA}

recorrentes (presentes como categorias, fatores, variáveis, temas) [...]” (MERRIAM, 2009, p. $38)$.

Nessa linha, o grupo de sujeitos da pesquisa foi composto por nove gestores, oriundos de oito empresas de base tecnológica (Quadro 3). No momento da coleta dos dados, realizada nos meses de abril e maio de 2019, a maior parte das empresas (sete), encontrava-se vinculada a incubadoras que desenvolvem programas de apoio ao desenvolvimento de novos negócios. Salienta-se, contudo, que este elemento do contexto de atuação dos gestores não foi diretamente pesquisado, ainda que se reconheça sua importância para a ampliação da compreensão do tema.

Quadro 3 - Perfil dos sujeitos da pesquisa e caracterização das empresas em que atuam

\begin{tabular}{|c|c|}
\hline Sujeito & Caracterização do entrevistado e da empresa \\
\hline E1 & $\begin{array}{l}\text { Homem, } 49 \text { anos, é CFO (chief financial officer) e sócio da empresa. Ele é graduado em ciências da } \\
\text { computação. A empresa tem cinco anos de operação e comercializa um serviço de provador virtual } \\
\text { para e-commerces de moda. Atuam na empresa, entre sócios e empregados, } 12 \text { pessoas. }\end{array}$ \\
\hline E2 & $\begin{array}{l}\text { Homem, } 47 \text { anos, é CEO (chief executive officer) e sócio da empresa. Ele tem formação superior em } \\
\text { marketing. A empresa tem três anos de operação e comercializa um sistema de gestão de benefícios } \\
\text { corporativos. Atuam na empresa, entre sócios, empregados e colaboradores, sete pessoas. }\end{array}$ \\
\hline E3 & $\begin{array}{l}\text { Homem, } 25 \text { anos, é CEO e sócio da empresa. Ele é graduado em sistemas de informação. A empresa } \\
\text { tem um ano e meio de operação, e comercializa uma plataforma informatizada voltada à análise e } \\
\text { melhoria de processos de trabalho. Atuam na empresa, entre sócios e empregados, seis pessoas. }\end{array}$ \\
\hline E4 & $\begin{array}{l}\text { Mulher, } 42 \text { anos, e é CEO e sócia da empresa. Ela é graduada em química. A empresa tem pouco } \\
\text { mais de um ano de operação e está na fase de desenvolvimento de uma solução, em nanotecnologia, } \\
\text { voltada à saúde humana. Atuam na empresa, entre sócios e colaboradores, quatro pessoas. }\end{array}$ \\
\hline E5 & $\begin{array}{l}\text { Homem, } 47 \text { anos, e é CEO e sócio da empresa. Ele é graduado em engenharia mecânica. A empresa } \\
\text { tem três anos de operação e comercializa um sistema de gestão da produção. Atuam na empresa, entre } \\
\text { sócios e colaboradores, seis pessoas. }\end{array}$ \\
\hline E6 & $\begin{array}{l}\text { Homem, } 39 \text { anos, e é diretor técnico e sócio da empresa. Ele é graduado em engenharia ambiental. A } \\
\text { empresa tem dez anos de operação e, além de oferecer serviços em gestão ambiental, desenvolve uma } \\
\text { tecnologia para tratamento de esgotos. Atuam na empresa, entre sócios e colaboradores, três pessoas. }\end{array}$ \\
\hline E7 & $\begin{array}{l}\text { Homem, } 31 \text { anos, e é CEO e sócio da empresa. Ele é graduado em design. A empresa tem dois anos } \\
\text { de operação, e comercializa um sistema de gestão e processamento de pagamentos. Atuam na } \\
\text { empresa, entre sócios, empregados e colaboradores, } 11 \text { pessoas. }\end{array}$ \\
\hline E8 & $\begin{array}{l}\text { Homem, } 27 \text { anos, e é diretor e sócio da empresa. Ele é graduado em engenharia de produção. A } \\
\text { empresa tem três anos de operação e comercializa uma plataforma para a gestão do desempenho } \\
\text { humano. Atuam na empresa, entre sócios e colaboradores, cinco pessoas. E8 e E9 são sócios. }\end{array}$ \\
\hline E9 & $\begin{array}{l}\text { Mulher, } 26 \text { anos, e é diretora e sócia da empresa. Ela é graduada em engenharia de produção. A } \\
\text { empresa tem três anos de operação e comercializa uma plataforma para a gestão do desempenho } \\
\text { humano. Atuam na empresa, entre sócios e colaboradores, cinco pessoas. E9 e E8 são sócios. }\end{array}$ \\
\hline
\end{tabular}

Fonte: elaboração própria.

A seleção dos entrevistados baseou-se no seguinte critério: ocupar uma posição gerencial em uma empresa de base tecnológica que esteja, preferencialmente, em estágio inicial de desenvolvimento (até cinco anos de operação).

A coleta dos dados deu-se por meio de entrevistas qualitativas individuais, técnica que se mostrou adequada, em especial, por sua característica de maleabilidade do diálogo entre o pesquisador e os sujeitos (GASKELL, 2002). Com isso, durante as entrevistas, as perguntas feitas aos participantes basearam-se em um tópico guia, formulado, principalmente, a partir da 
literatura que orientou a investigação e, em parte, por questões de interesse dos pesquisadores. Do tópico guia constaram os seguintes itens: a) função exercida, na empresa; b) a ocorrência de erros durante a execução do próprio trabalho; c) relato de uma situação em que o participante cometeu um erro, na execução de seu trabalho (o que foi o erro, como identificou o erro, reação pessoal ao constatar o erro, causas do erro, se compartilhou a ocorrência do erro e ações corretivas); d) aprendizados obtidos a partir da situação de erro e o que colaborou para a aprendizagem.

Como sugerido por Gaskell (2002), o tópico guia foi utilizado com flexibilidade, ou seja, a formulação das perguntas, por vezes, foi adaptada ao contexto específico da sessão de entrevista, como nos casos e que perguntas complementares são necessárias para incentivar o participante a fornecer informações mais detalhadas sobre o assunto. Das nove entrevistas, oito foram realizadas presencialmente, na empresa do entrevistado, e uma ocorreu via chamada de vídeo, pelo Skype, sendo que os intervalos de duração das sessões situaram-se entre 40 e 60 minutos, aproximadamente, exceto para uma sessão, que teve a duração de 31 minutos. Em relação à saturação dos dados, esta ocorreu com a realização das duas entrevistas finais, quando se observou que os relatos dos sujeitos traziam elementos semelhantes aos das entrevistas anteriores. Avalia-se que a saturação tenha ocorrido com nove sujeitos, apenas, devido à forma pela qual o campo da pesquisa foi delimitado.

No tratamento e análise dos dados, foram adotados os procedimentos da análise de conteúdo, em com constância com o exposto por Bauer (2002) e Creswell (2014). A partir dos arquivos de registro do áudio das entrevistas, um dos pesquisadores fez a transcrição integral do conteúdo das entrevistas, o que gerou 60 páginas de corpus de texto (texto digitado em fonte Times New Roman 12 e em espaçamento simples). Após isto, o primeiro passo da exploração inicial dos dados envolveu a leitura, por inteiro, de cada uma das transcrições, com a intenção de obter-se uma visão geral das entrevistas e de formular as primeiras opiniões obre os relatos dos participantes, registradas em anotações à parte das transcrições.

Como segundo passo da exploração inicial dos dados, para cada sujeito da pesquisa, foi elaborada uma descrição, cronologicamente organizada, dos eventos relativos à situação de erro relatada, o que gerou, portanto, nove descrições de situações de erros cometidos pelos entrevistados, cada uma com, aproximadamente, entre meia página uma página de texto. Este procedimento permitiu a visualização dos eventos, associados às situações de erro, de forma contextualizada e numa perspectiva processual da ocorrência do fenômeno, em certa medida, em consonância com o modo pelo qual o tópico guia foi elaborado. Com isso, em alinhamento com o entendimento proposto por Gaskell (2002), a estrutura do tópico guia foi tomada como 
esquema preliminar de codificação dos elementos do corpus de texto, em que prevaleceram as seguintes categorias: a) erro cometido; b) o que ajudou na identificação do erro; c) causas do erro; d) comunicação ou não do erro; e) aprendizados; f) o que ajudou na aprendizagem.

O processo de codificação foi feito a partir do formato digital dos textos, em Word, com o auxílio do editor de planilhas Excel. À medida que as categorias eram identificadas, a unidades de texto eram copiadas e coladas numa planilha, de acordo com a sua categoria.

Posteriormente, mediante a análise de cada categoria, foram registradas as subcategorias que emergiram da análise do corpus de texto. Por fim, após a interpretação das categorias e suas subcategorias - mediante a renomeação e fusão de categorias, e a criação de uma nova gerou-se um esquema final de categorias temáticas oriundas dos relatos dos participantes, que se mostrou mais pertinente ao arcabouço teórico da pesquisa. As categorias finais foram definidas da seguinte forma: a) erro cometido; b) situação-problema em que o erro se manifestou; c) comunicação do erro; d) causas do erro; e) medidas corretivas adotadas; f) elementos do contexto que facilitaram a abordagem ao erro; g) aprendizados adquiridos a partir da situação de erro.

Na sequência, a apresentação, análise e discussão dos dados são feitas a partir de tais categorias e seus elementos. Em tempo, salienta-se que, na apresentação dos dados, não se priorizou a inserção de citações das falas dos sujeitos, pela observância do limite máximo da extensão do trabalho.

\section{ANÁLISE E DISCUSSÃo DOS RESULTADOS}

\subsection{A ocorrência do erro e a sua detecção}

O Quadro 4 descreve o erro relatado por cada um dos sujeitos da pesquisa, bem como a situação-problema por meio da qual o erro se manifestou, ou seja, o momento em que o sujeito foi alertado sobre ou constatou alguma divergência entre o que se esperava realizar e o que foi alcançado, sem, necessariamente, ter consciência de que se tratava de um erro individual.

Como se observa, os episódios de erro abrangem diferentes processos e atividades organizacionais, como implantação de novos negócios, desenvolvimento de novos produtos, gerenciamento de projetos, contratação de serviços de terceirizados, distribuição de atividades e responsabilidades entre os membros da equipe, vendas e marketing, e comunicação interpessoal. Trata-se de questões, normalmente, presentes no contexto de atuação das empresas 
em seus primeiros anos de existência, relativas ao planejamento e à gestão do negócio, e que são determinantes à perenidade da organização (SEBRAE, 2016).

Quadro 4 - Erros cometidos pelos sujeitos da pesquisa e situações-problema em que se manifestaram

\begin{tabular}{|c|c|c|}
\hline Sujeito & Erro & Situação-problema em que o erro se manifestou \\
\hline E1 & $\begin{array}{l}\text { Erro na determinação dos fatores de } \\
\text { decisão de compra pelo potencial cliente, } \\
\text { os quais orientariam as abordagens de } \\
\text { venda aos potenciais clientes. }\end{array}$ & $\begin{array}{l}\text { Durante as primeiras visitas de prospecção de } \\
\text { clientes, E1 constatou que os benefícios do produto } \\
\text { que ele procurava enfatizar, durante a apresentação } \\
\text { do produto, não eram aspectos considerados } \\
\text { relevantes por alguns dos potenciais clientes, os } \\
\text { quais, normalmente, declinavam da proposta de } \\
\text { aquisição do produto. }\end{array}$ \\
\hline E2 & $\begin{array}{l}\text { Erro na definição da estratégia de } \\
\text { abordagem ao potencial cliente, baseada na } \\
\text { premissa de que, sempre que possível, o } \\
\text { contato inicial e a apresentação do produto } \\
\text { deveriam ser feitos ao proprietário ou } \\
\text { principal dirigente da empresa, por este ser } \\
\text { quem decidiria pela compra. }\end{array}$ & $\begin{array}{l}\text { Ao longo da negociação com um potencial cliente, E2 } \\
\text { notou que a decisão de compra dependia, igualmente, } \\
\text { do gestor da área para a qual a aplicação do produto } \\
\text { destinava-se. Isto ocorreu quando o gestor da área } \\
\text { interrompeu o processo de negociação, ainda que } \\
\text { houvesse sido uma atividade delegada pelo presidente } \\
\text { da empresa. }\end{array}$ \\
\hline E3 & $\begin{array}{l}\text { Erro na precificação do produto e no } \\
\text { processo de venda, pela não comunicação } \\
\text { dos benefícios gerados pelo produto, } \\
\text { durante as abordagens aos potenciais } \\
\text { clientes. }\end{array}$ & $\begin{array}{l}\text { Durante as abordagens comerciais junto aos } \\
\text { potenciais clientes, E3 constatou que estes tendiam a } \\
\text { reagir de modo negativo ante a informação do preço } \\
\text { do produto, em parte, por não conhecerem os } \\
\text { benefícios gerados pelo produto. }\end{array}$ \\
\hline E4 & $\begin{array}{l}\text { Erro no processo de avaliação e } \\
\text { planejamento do novo negócio, por não } \\
\text { terem sido feitas a pesquisa e a análise de } \\
\text { informações sobre a concorrência. }\end{array}$ & $\begin{array}{l}\text { Ao participar de um programa de desenvolvimento de } \\
\text { novos negócios, o plano de negócio de E4 foi } \\
\text { avaliado pelos mentores de negócio do programa, os } \\
\text { quais evidenciaram que diversas informações } \\
\text { relevantes ao desenvolvimento do novo negócio não } \\
\text { haviam sido levadas em conta. }\end{array}$ \\
\hline E5 & $\begin{array}{l}\text { Erro no processo de comunicação } \\
\text { interpessoal, por não agir de modo } \\
\text { empático com um dos sócios }\end{array}$ & $\begin{array}{l}\text { Logo após o início das operações da empresa, muitos } \\
\text { conflitos interpessoais ocorreram entre E5 e um de } \\
\text { seus sócios, que emergiam, principalmente, quando } \\
\text { de comunicações via WhatsApp, relativas à } \\
\text { operacionalização e a tomadas de decisão sobre } \\
\text { questões diversas do negócio. }\end{array}$ \\
\hline E6 & $\begin{array}{l}\text { Erros no gerenciamento de um projeto, } \\
\text { representados, de um lado, pela não } \\
\text { formalização de parte dos acordos técnico- } \\
\text { operacionais feitos e, de outro, pelo } \\
\text { excesso de concessões feitas ao } \\
\text { contratante, durante os conflitos } \\
\text { contratuais e interpessoais. }\end{array}$ & $\begin{array}{l}\text { No decorrer do desenvolvimento do projeto, em } \\
\text { diversas ocasiões, E6 foi instado, pelo cliente, a } \\
\text { realizar atividades que não constavam dos termos } \\
\text { contratuais do projeto - as quais, normalmente, ele } \\
\text { cumpria e implicaram em retrabalho e aumento de } \\
\text { custos do projeto. Também, durante as reuniões com } \\
\text { a equipe do cliente, começaram a ocorrer conflitos } \\
\text { interpessoais. }\end{array}$ \\
\hline E7 & $\begin{array}{l}\text { Erro na contratação do prestador de } \\
\text { serviços contábeis, cujos critérios de } \\
\text { seleção não se mostraram adequados à } \\
\text { garantia da qualidade dos serviços } \\
\text { prestados. }\end{array}$ & $\begin{array}{l}\text { Decorridos alguns meses da contratação, o prestador } \\
\text { de serviços de contabilidade começou a apresentar } \\
\text { dificuldades para fornecer, no tempo adequado, os } \\
\text { demonstrativos contábeis do negócio, documentos } \\
\text { imprescindíveis ao relacionamento com bancos e } \\
\text { investidores. }\end{array}$ \\
\hline E8 & $\begin{array}{l}\text { Erro na validação da ideia de negócio e no } \\
\text { desenvolvimento de novo produto, por tais } \\
\text { processos terem sido orientados, } \\
\text { exclusivamente, pela visão de E8 e de seus } \\
\text { sócios, e não com base em informações do } \\
\text { mercado consumidor. }\end{array}$ & $\begin{array}{l}\text { Após se dedicar, por um ano e meio, ao } \\
\text { desenvolvimento do novo produto, este ainda não } \\
\text { apresentava condições para ser comercializado. } \\
\text { Concomitante, E8 verificou que o produto não } \\
\text { possuía viabilidade econômico-financeira e, assim, } \\
\text { não representava uma oportunidade de negócio. }\end{array}$ \\
\hline
\end{tabular}

(CONTINUA) 


\section{(CONTINUAÇÃO)}

\begin{tabular}{|c|l|l|}
\hline E9 & $\begin{array}{l}\text { Erro na organização do trabalho, por } \\
\text { assumir a responsabilidade pela execução } \\
\text { de uma atividade para a qual não possuía } \\
\text { aptidão (venda do produto). }\end{array}$ & $\begin{array}{l}\text { Após três semanas, durante as quais E9 executou as } \\
\text { atividades de vendas, ela foi interpelada por seu sócio } \\
\text { em relação aos resultados de vendas, os quais não se } \\
\text { mostravam positivos. }\end{array}$ \\
\hline
\end{tabular}

Fonte: elaboração própria.

Também, as situações relatadas refletem elementos característicos do erro, em consonância com suas definições, encontradas na literatura. Nessa perspectiva, descrevem situações em que decisões ou formas de agir levaram a um desvio não intencional de resultados que se esperavam alcançar (ZHAO; OLIVERA, 2006; VAN DYCK et al. 2005), representadas pela não efetivação de vendas (E1, E2 e E3) ou por falhas no gerenciamento de um projeto de grande porte (E6). Igualmente, se verifica que parte dos erros descrevem situações cujas consequências evidenciam algum impacto negativo no desempenho organizacional (GOODMAN et al., 2011; LEI et al. 2016), como o cancelamento do lançamento de um novo produto (E8) e o não cumprimento de exigências legais junto aos parceiros do negócio (E7).

Outros episódios caracterizam-se como erros, especialmente, pela demonstração de que o resultado obtido, avaliado como negativo, indicava o não alcance de uma meta (E5) ou, mesmo, um obstáculo ao alcance de objetivos de ordem superior (Bauer e Mulder, 2007) como a decisão pela constituição de um novo negócio sem se levar em conta informações sobre a concorrência (E4). Também, se verifica o erro retratado por falhas no relacionamento interpessoal (CANNON; EDMONDSON, 2001), como na situação em que o sujeito não agiu de modo empático na comunicação com seu sócio (E5).

Por meio das situações-problema, é possível evidenciar, de modo mais específico, elementos indicativos da ocorrência de um erro, que se constituem em resultados negativos, obstáculos à concretização de uma tarefa ou mau funcionamento de um processo de trabalho.

Quadro 5 - Elementos indicativos da ocorrência de erros, conforme relatos dos sujeitos

\begin{tabular}{|c|c|c|}
\hline Sujeito & Elemento indicativo do erro & Natureza de elemento \\
\hline E1 & $\begin{array}{l}\text { Reações negativas de potenciais clientes à abordagem de vendas, } \\
\text { associadas à não efetivação da venda }\end{array}$ & $\begin{array}{l}\text { Feedback de outras } \\
\text { pessoas } \\
\text { Indicador de } \\
\text { desempenho }\end{array}$ \\
\hline E2 & $\begin{array}{l}\text { Interrupção do processo de negociação pelo potencial cliente, o que } \\
\text { levou à não efetivação da venda no prazo esperado }\end{array}$ & $\begin{array}{l}\text { Feedback de outras } \\
\text { pessoas } \\
\text { Indicador de } \\
\text { desempenho }\end{array}$ \\
\hline E3 & $\begin{array}{l}\text { Reações negativas de potenciais clientes à abordagem de vendas, } \\
\text { associada à não efetivação da venda }\end{array}$ & $\begin{array}{l}\text { Feedback de outras } \\
\text { pessoas }\end{array}$ \\
\hline E4 & Avaliação e questionamentos de especialistas (mentores de negócios) & $\begin{array}{l}\text { Parecer e opinião de } \\
\text { especialistas }\end{array}$ \\
\hline E5 & Conflitos interpessoais com o sócio & Conflito interpessoal \\
\hline
\end{tabular}


(CONTINUAÇÃO)

\begin{tabular}{|c|l|l|}
\hline E6 & $\begin{array}{l}\text { Ocorrência de retrabalho e de aumento de custos do projeto } \\
\text { desenvolvido junto ao cliente } \\
\text { Conflitos interpessoais com a equipe do cliente }\end{array}$ & $\begin{array}{l}\text { Indicador de } \\
\text { desempenho } \\
\text { Conflito interpessoais }\end{array}$ \\
\hline E7 & Não cumprimento de prazos de entrega pelo prestador de serviços & $\begin{array}{l}\text { Indicador de } \\
\text { desempenho }\end{array}$ \\
\hline E8 & $\begin{array}{l}\text { Adiamentos sucessivos do lançamento do novo produto ao mercado } \\
\text { Avaliação e questionamentos de especialistas (mentores de negócios) }\end{array}$ & $\begin{array}{l}\text { Indicador de } \\
\text { desempenho } \\
\text { Parecer e opinião de } \\
\text { especialistas }\end{array}$ \\
\hline E9 & $\begin{array}{l}\text { Não alcance das metas de vendas } \\
\text { Questionamento, por parte do sócio, sobre o andamento da atividade e de } \\
\text { seus resultados }\end{array}$ & $\begin{array}{l}\text { Indicador de } \\
\text { desempenho } \\
\text { Feedback de outras } \\
\text { pessoas }\end{array}$ \\
\hline
\end{tabular}

Fonte: elaboração própria.

Como se observa no Quadro 5, a partir dos relatos dos sujeitos, identificam-se quatro tipos de elementos indicativos de um erro: feedback de outras pessoas, indicadores de desempenho, pareceres e opiniões de especialistas, e ocorrência de conflitos interpessoais.

Os feedbacks emitidos por outras pessoas (E1, E3 e E9) são apontados, na literatura, como um dos elementos que contribuem para a identificação de erro (CANNON; EDMONDSON, 2001; LOVE; JOSEPHSON, 2004) e, no caso dos episódios de erro, foram oriundos, principalmente, de pessoas externas às organizações (potenciais clientes). Os conflitos interpessoais (E5 e E6) são vistos como uma falha em si (CANNON; EDMONDSON, 2001), contudo, na visão dos sujeitos, o conflito interpessoal emerge como um indicativo de que um erro pode ter sido cometido. O monitoramento, ainda que de modo informal, de indicadores de desempenho (E1, E2, E6, E7, E8 e E9) mostrou-se o elemento indicativo de erro mais recorrente, possivelmente, por sua finalidade de evidenciar o alcance de metas ou objetivos. Por fim, observa-se a busca da opinião de especialistas (E4 e E8) como outro indicativo de erro.

Salienta-se que a função destes elementos, menos do que apontar o erro cometido, é a sinalizar a existência de um problema na situação ou processo de trabalho, cuja investigação e análise poderão encaminhar à detecção de um erro, gerador do problema que impacta o alcance de um resultado ou o cumprimento de uma tarefa. O feedback recebido por E3, de seu cliente, indicava que havia algum problema relativo ao preço do serviço e não o erro de E3 na forma de comunicar o preço; assim como, o monitoramento dos prazos de entrega dos demonstrativos contábeis, por E7, acusou um problema que envolvia o prestador de serviços contábeis e não o erro de E7 na contratação deste. 
Nessa linha, a efetiva detecção dos erros, pelos próprios sujeitos, deu-se após um período de reflexão, e de busca e análise de informações atinentes à situação de problema. $\mathrm{Na}$ próxima seção, o foco recai sobre como os sujeitos lidaram com a decisão sobre compartilhar ou não a ocorrência dos erros.

\subsection{O compartilhamento da ocorrência do erro}

Após a detecção do erro, todos os sujeitos relataram ter compartilhado a sua ocorrência com outras pessoas, internas à organização, como sócios e membros da equipe. Acredita-se que as pessoas, em seu trabalho, têm a propensão para fazer uma avaliação consciente sobre as potenciais decorrências, positivas e negativas, que podem advir do compartilhamento da ocorrência do erro, em especial, com seus superiores (ZHAO; OLIVERA, 2006). Os sujeitos da pesquisa, por outro lado, relatam não ter considerado a possibilidade de omitir o erro, atitude que pode ter sido motivada pela posição gerencial ocupada por eles e, nos casos em que havia algum superior, este era, também, um sócio do negócio, o que pode ter-lhes conferido mais segurança para reportar o erro.

Harteis, Bauer e Gruber (2008, p. 228) coletaram evidências que sugerem haver diferenças na forma pela qual gestores e empregados lidam com os próprios erros, em que "[...] gestores tendem a ver o aprendizado a partir dos erros no trabalho cotidiano de maneira mais positiva que os empregados", possivelmente, pelo maior grau de liberdade que têm para cometer erros e abordá-los de modo positivo (HARTLEY, 2000 apud HARTEIS; BAUER; GRUBER, 2008). Além disso, os erros relatados, em sua maior parte, foram associados a impactos negativos no resultado do negócio, como a não captação de novos clientes, não realização de vendas e o aumento de custos da operação. A avalição dos erros como graves e com alto nível de severidade dos danos (HOMSMA et al., 2009), também, podem ter influenciado a predisposição dos sujeitos da pesquisa para comunicar ou compartilhar a ocorrência dos erros.

No processo de recuperação de erros proposto por Sasou e Reason (1999), dentre as etapas previstas (detecção, indicação e correção), a da indicação diz respeito à comunicação do erro aos membros da equipe, por quem o detectou; se isto não ocorrer, o erro poderá não ser tratado e seus efeitos continuarão persistindo. Tomando tal referência, observa-se que o ato de comunicar a ocorrência do erro, como relatado pelos sujeitos da pesquisa, trata-se de um estágio 
análogo ao da indicação, mediante o que pode ter início o estágio de correção de um erro que, em termos práticos, dá-se a partir da identificação de suas causas.

\section{3 identificação das causas dos erros}

O consenso que vem formando-se em relação ao fenômeno, expresso por meio de suas definições, sinaliza o entendimento de que o erro diz respeito a um evento evitável ou, pelo menos, potencialmente evitável (CANNON; EDMONDSON, 2001; ZHAO; OLIVERA, 2006; LEI et al., 2016) e, mediante os relatos dos sujeitos, observou-se que a identificação da causa do erro é um elemento crítico à compreensão do evento e, logo, de sua evitabilidade. No Quadro 6, são listadas as causas para os erros por eles relatados, sendo que, para a maior parte dos erros, foram indicadas duas ou mais causas para o mesmo erro, as quais, por vezes, mostram-se interrelacionadas (é caso, por exemplo, de E1, que aponta duas causas relacionadas à forma da tomada de decisão).

Quadro 6 - Causas dos erros relatados pelos sujeitos da pesquisa e seus tipos

\begin{tabular}{|c|c|c|}
\hline Sujeito & Causas do erro & Tipo de causa \\
\hline E1 & $\begin{array}{l}\text { Desconhecimento dos reais benefícios gerados pelo serviço } \\
\text { comercializado } \\
\text { Processo de tomada de decisão pouco analítico } \\
\text { Pressa na tomada de decisão }\end{array}$ & $\begin{array}{l}\text { Informação incompleta } \\
\text { Execução inadequada do } \\
\text { processo de trabalho } \\
\text { Execução inadequada do } \\
\text { processo de trabalho }\end{array}$ \\
\hline E2 & $\begin{array}{l}\text { Pressuposto sobre o comportamento do cliente } \\
\text { Desejo de executar a atividade de forma rápida }\end{array}$ & $\begin{array}{l}\text { Informação ou conhecimento } \\
\text { errôneo } \\
\text { Execução inadequada do } \\
\text { processo de trabalho }\end{array}$ \\
\hline E3 & $\begin{array}{l}\text { Falta de experiência e de conhecimentos em gestão empresarial } \\
\text { Pouca informação sobre as práticas comerciais dos concorrentes }\end{array}$ & $\begin{array}{l}\text { Falta de conhecimento ou de } \\
\text { habilidade } \\
\text { Informação incompleta }\end{array}$ \\
\hline E4 & $\begin{array}{l}\text { Foco da atuação profissional pregressa em áreas tecnológicas } \\
\text { Falta de conhecimentos sobre mercado } \\
\text { Aprendizagem prévia errônea }\end{array}$ & $\begin{array}{l}\text { Falta de conhecimento ou de } \\
\text { habilidade } \\
\text { Falta de conhecimento ou de } \\
\text { habilidade } \\
\text { Informação ou conhecimento } \\
\text { errôneo }\end{array}$ \\
\hline E5 & $\begin{array}{l}\text { Não saber relacionar-se com os profissionais de tecnologia, das } \\
\text { novas gerações }\end{array}$ & $\begin{array}{l}\text { Falta de conhecimento ou de } \\
\text { habilidade }\end{array}$ \\
\hline E6 & $\begin{array}{l}\text { Pouco conhecimento sobre gerenciamento de projetos } \\
\text { Falta de conhecimento sobre gestão de conflitos contratuais }\end{array}$ & $\begin{array}{l}\text { Falta de conhecimento ou de } \\
\text { habilidade } \\
\text { Falta de conhecimento ou de } \\
\text { habilidade }\end{array}$ \\
\hline E7 & $\begin{array}{l}\text { Falta de experiência como empresário e de conhecimento sobre } \\
\text { como gerenciar uma empresa } \\
\text { Necessidade de executar as tarefas de forma rápida, em } \\
\text { decorrência do acúmulo de responsabilidades }\end{array}$ & $\begin{array}{l}\text { Falta de conhecimento ou de } \\
\text { habilidade } \\
\text { Execução inadequada do } \\
\text { processo de trabalho }\end{array}$ \\
\hline
\end{tabular}

(CONTINUA) 


\begin{tabular}{|c|l|l|} 
(CONTINUAÇÃO) \\
\hline E8 & $\begin{array}{l}\text { Aprendizagem prévia errônea } \\
\text { Não buscar informações junto a outros atores do mercado, como } \\
\text { outros empreendedores, clientes e especialistas }\end{array}$ & $\begin{array}{l}\text { Informação ou conhecimento } \\
\text { errôneo } \\
\text { Falta de conhecimento ou de } \\
\text { habilidade }\end{array}$ \\
\hline E9 & $\begin{array}{l}\text { Entendimento de que era preciso economizar recursos } \\
\text { financeiros por meio da não contratação de um empregado }\end{array}$ & $\begin{array}{l}\text { Falta de conhecimento ou de } \\
\text { habilidade }\end{array}$ \\
\hline
\end{tabular}

Fonte: elaboração própria.

Observa-se que, ainda que sejam descritas de formas distintas, as causas identificadas podem ser agregadas, de modo indutivo, em alguns pouco tipos comuns de causas, quais sejam falta de conhecimento ou de habilidade, informação incompleta, informação ou conhecimento errôneo ou execução inadequada do processo de trabalho. A falta de conhecimento ou de habilidade diz respeito a situações como a relatada por E3, para quem o erro cometido foi por "[...] por inexperiência, falta de conhecimento. Nosso background era muito técnico e a gente sabe que, quando alguém muito técnico começa a assumir essas outras funções de gestão, tem que buscar essa capacitação". Isso implica em que, apesar do pouco conhecimento ou escassa vivência profissional atinente ao novo contexto de trabalho, os sujeitos, ainda assim, encontravam-se em uma posição que lhe exigiam a tomada de decisão e desempenho de atribuições relativas a questões gerenciais e mercadológicas.

A informação incompleta como causa do erro pode ser ilustrada pelo relato de E1, que atribui a causa do erro à sua concepção de que "[...] o cliente nos escolheria por causa de uma coisa, que era redução de troca e devolução, e percebemos que a maioria dos clientes, hoje, nos contrata para aumentar a venda". A informação, em tais casos, é relativa ao tipo de conhecimento que é adquirido, em especial, por meio da experimentação em um contexto específico, geralmente, relacionado a projetos inovadores (CANNON; EDMONDSON, 2001). A informação é incompleta pois, possivelmente, não poderia ter sido adquirida, anteriormente.

Os erros que têm origem em informação ou conhecimento errôneos são representados pelo episódio descrito por E8, em que ele acreditava ter o conhecimento adequado para lidar com os desafios oriundos do desenvolvimento de um novo produto: "Na faculdade, tinha um professor de desenvolvimento de produtos, mas ele tinha a mesma visão: eu sento numa prancheta, desenvolvo um produto por anos e, depois, eu jogo ele para o mercado. Foi dessa forma que a gente aprendeu, mesmo algumas pessoas falando que não é assim” (E8). A informação ou conhecimento errôneo é aquele que se julga ser a premissa ou o padrão que deve ser adotado para a tomada de decisão ou a execução de uma tarefa; a forma de lidar com a situação está em conformidade com o parâmetro adotado, mas este, contudo, é equivocado. 
Finalmente, a execução inadequada do processo de trabalho como causa do erro diz respeito às situações em que o sujeito, apesar de conhecer o modo correto de cumprir uma atividade, a realiza de modo diferente ou incompleto, como relata E2: "Eu era responsável por várias coisas, ao mesmo tempo: eu era designer, $C E O$, tinha que cuidar da parte financeira, fazer negociação com os investidores, com a contabilidade... E [...] acabei fazendo coisas mais rápido, para resolver, que acabam gerando erros [...]”. Tal relato remete ao tipo de erro designado por deslizes ou enganos (Reason, 1990) e que, normalmente, decorrem de falta de atenção ou de enganos provocados por fatores contextuais.

Como sugere Reason (1990, p. 12), o “[...] o termo tipo de erro é relativo à origem presumida de um erro, nas etapas envolvidas na concepção e realização de uma sequência de ações", ou seja, de uma atividade ou tarefa. Nessa perspectiva, as causas identificadas para os erros relatados pelos sujeitos da pesquisa podem ser tomadas como referencial para a classificação dos erros por tipo, com vistas ao desenvolvimento de modelos para a abordagem ao erro.

\subsection{A implantação de medidas corretivas}

O processo de aprendizagem a partir de um erro ocorre, de modo mais intensivo, à medida que as ações corretivas são concebidas, planejadas e implementadas. Como se evidencia por meio do Quadro 7, excluindo-se E4 e E5, os demais sujeitos da pesquisa adotaram ações voltadas à correção do erro e, no momento das entrevistas, já haviam implementado e avaliado os resultados das ações, cujos efeitos, de forma geral, mostraram-se positivos.

Quadro 7 - Medidas corretivas adotadas e elementos contextuais que ajudaram na abordagem à situação de erro

\begin{tabular}{|c|l|l|}
\hline Sujeito & \multicolumn{1}{|c|}{ Medidas corretivas adotadas } & $\begin{array}{c}\text { Elementos contextuais que ajudaram a } \\
\text { lidar com a situação de erro }\end{array}$ \\
\hline E1 & $\begin{array}{l}\text { Alteração da forma de apresentação do produto aos } \\
\text { potenciais }\end{array}$ & $\begin{array}{l}\text { Troca de experiência com pessoas de outras } \\
\text { empresas, em estágio similar ou mais } \\
\text { avançado }\end{array}$ \\
\hline E2 & Alteração da abordagem inicial a potenciais clientes & Troca de ideias com sócios \\
\hline E3 & $\begin{array}{l}\text { Alteração da forma de apresentação do preço do } \\
\text { produto e dos serviços agregados, aos potenciais } \\
\text { clientes }\end{array}$ & $\begin{array}{l}\text { Discussão do assunto com os sócios } \\
\text { Orientação com mentor de negócios } \\
\text { Conversas com profissionais de outras } \\
\text { empresas, cujos negócios sejam similares }\end{array}$ \\
\hline E4 & Busca e análise de informações de mercado & $\begin{array}{l}\text { Orientação com mentor de negócios } \\
\text { Cursos de desenvolvimento de negócios }\end{array}$ \\
\hline E5 & Não houve a adoção de medidas corretivas & - \\
\hline
\end{tabular}

(CONTINUA) 


\section{(CONTINUAÇÃO)}

\begin{tabular}{|c|l|l|}
\hline E6 & $\begin{array}{l}\text { Adoção de novos comportamentos nos processos de } \\
\text { gerenciamento do projeto, e de coordenação da } \\
\text { equipe }\end{array}$ & $\begin{array}{l}\text { Orientação com amiga que possuía } \\
\text { experiência em gestão de contratos } \\
\text { Troca de ideias com um dos membros da } \\
\text { equipe de trabalho }\end{array}$ \\
\hline E7 & $\begin{array}{l}\text { Contratação de um novo prestador de serviços } \\
\text { contábeis }\end{array}$ & $\begin{array}{l}\text { Tomada de decisão conjuntamente com os } \\
\text { sócios } \\
\text { Orientação de mentor de negócios }\end{array}$ \\
\hline E8 & $\begin{array}{l}\text { Identificação de uma nova oportunidade de negócio } \\
\text { e alteração do processo de desenvolvimento de } \\
\text { novos produtos }\end{array}$ & $\begin{array}{l}\text { Programa de capacitação para geração de } \\
\text { novos negócios } \\
\text { Troca de ideias com a sócia } \\
\text { Orientação de mentor de negócios }\end{array}$ \\
\hline E9 & $\begin{array}{l}\text { Contratação de um empregado para assumir a } \\
\text { execução das atividades de vendas }\end{array}$ & $\begin{array}{l}\text { Tomada de decisão conjuntamente com o } \\
\text { sócio }\end{array}$ \\
\hline
\end{tabular}

Fonte: elaboração própria.

Em relação a E4, no momento da coleta de dados para esta pesquisa, a ação corretiva encontra-se em sua fase inicial de implementação. No caso de E5, ele mencionou algumas tentativas que fez para lidar com os conflitos recorrentes com o sócio. Por vezes, ele buscava conversar com o sócio, para buscar entender o que havia ocorrido; em outras ocasiões, ele pedia a um dos outros sócios que fizesse a mediação da comunicação entre os dois. Tais ações, contudo, não eliminaram as situações de conflito e, no entendimento de E5, o erro foi corrigido, realmente, quando o sócio se retirou do negócio: “[...] ele preferiu sair da sociedade. Eu acabei não só mitigando esse erro aí, mas eliminando de vez, porque o cara não está mais com a gente”.

Ainda que situações de conflitos interpessoais possam ser apontadas como sendo de erro (CANNON; EDMONDSON, 2001), o relato de E5 sinaliza a complexidade contida na atribuição da "culpabilidade individual" (LOVE; JOSEPHSON, 2004, p. 71) pelos erros em situações de interações pessoais. Embora E5 tenha atribuído a si a responsabilidade pelo erro que ele definiu como "[...] não estar me colocando no lugar dele para entender o que ele entendeu [...]", talvez, ele não tivesse convicção de sua culpabilidade, o que se denota quando ele pondera que poderia "[...] ser o contrário, também, ele que estava errado e eu estava certo" (E5). Tal perspectiva se reforça tanto por sua dificuldade em identificar as condições sob as quais detectou o erro, quanto por sua visão sobre a forma pela qual o erro foi corrigido.

Diferentes elementos, do contexto de ação dos sujeitos, foram avaliados como importantes para o planejamento e implementação das medidas corretivas, como se verifica, também, no Quadro 7. Tais elementos podem ser ordenados em quatro categorias de recursos do contexto que facilitaram a abordagem à situação de erro. Primeiro, a discussão da situação com outras pessoas da organização é definida pelo compartilhamento e avaliação da situação junto aos sócios, bem como pela tomada de decisão de forma conjunta (E2, E3, E7, E8 e E9), além do compartilhamento da situação e troca de ideias com outros membros da equipe (E6). 
Já a busca de orientação junto a especialistas é representada, especialmente, pela busca de orientação junto a mentores de negócios, papel desempenhado por profissionais com mais experiência empresarial, acessados diretamente pelos sujeitos (E7) ou por meio de programas de mentoria disponibilizados pelas incubadoras às quais as empresas dos sujeitos encontravamse vinculadas (E3, E4 e E8). Também, a busca de orientação a especialistas mostra-se na forma de consulta a pessoas da rede de relacionamentos do sujeito, como o caso de E6.

As trocas de informação por meio de interações com pessoas externas à organização dizem respeito a, basicamente, a conversas com pessoas que atuam em negócios similares (E3) ou em empresas em estágio de desenvolvimento semelhante ou superior (E1), ainda que o negócio seja distinto. Por fim, a participação em cursos e programas de capacitação (E4 e E8), é relativa a programas de desenvolvimento de novos negócios, ofertados pelas incubadoras.

Estes elementos contextuais são apontados como importantes à abordagem às situações de erro pois representam as formas pelas quais os sujeitos obtiveram informações e conhecimentos relevantes ao desenvolvimento de novas estratégias de ação e, com isso, configuram-se, igualmente, em atividades de aprendizagem (Baudoin, 2004). Nessa perspectiva, é observa a ocorrência de aprendizagens formais (cursos e programas de capacitação, e programas de mentoria) e informais (discussões e trocas de informações com outras pessoas), bem como aprendizagens por meio do uso ativo de fontes internas à organização (sócios e outros membros da equipe de trabalho) e externas à organização (profissionais que atuam em outras empresas).

Desse modo, no Quadro 8, estão listados os aprendizados que os sujeitos adquiriram, a partir da abordagem à situação de erro. Em consonância com as definições encontradas na psicologia da aprendizagem (LEFRANÇOIS, 2012), são identificados quatro tipos de aprendizados, representados por conhecimentos técnico-operacionais, conhecimentos técnicogerenciais, habilidades comportamentais e compreensões e opiniões. É relevante notar que os aprendizados não se limitam à aquisição de informações, expressa na forma de conhecimentos, mas se mostram, também, na forma de novas compreensões e opiniões, ou seja, ideias individuais consistentes que guiam o comportamento e que espelham aprendizados obtidos por meio da reflexão sobre as próprias experiências (KOLB, 1984). 
Quadro 8 - Aprendizados adquiridos, pelos sujeitos, a partir da situação de erro

\begin{tabular}{|c|c|}
\hline Sujeito & Aprendizados adquiridos a partir da abordagem à situação de erro \\
\hline E1 & $\begin{array}{l}\text { Conhecimentos técnico-gerenciais: aquisição de informação à precificação } \\
\text { Compreensões e opiniões: aquisição da compreensão de que é preciso reconhecer e interpretar } \\
\text { informações distintas das que julga corretas (em relação às expectativas comunicadas pelos clientes) }\end{array}$ \\
\hline E2 & $\begin{array}{l}\text { Conhecimentos técnico-gerenciais: aquisição de informações sobre o processo de prospecção de } \\
\text { clientes }\end{array}$ \\
\hline E3 & $\begin{array}{l}\text { Conhecimentos técnico-operacionais: aprimoramento da abordagem pessoal junto ao potencial } \\
\text { cliente }\end{array}$ \\
\hline E4 & $\begin{array}{l}\text { Conhecimentos técnico-gerenciais: aquisição de conhecimentos de gestão mercadológica } \\
\text { Habilidades comportamentais: autoconfiança em relação à própria capacidade de aprender }\end{array}$ \\
\hline E5 & $\begin{array}{l}\text { Compreensões e opiniões: compreensão de que é preciso adotar uma forma diferente de relacionar-se } \\
\text { com as novas gerações }\end{array}$ \\
\hline E6 & $\begin{array}{l}\text { Conhecimentos técnico-gerenciais: aquisição de conhecimentos sobre coordenação de projetos e } \\
\text { sobre a função regulatória dos instrumentos contratuais }\end{array}$ \\
\hline E7 & $\begin{array}{l}\text { Compreensões e opiniões: aquisição da compreensão de que as atividades, na empresa, sejam } \\
\text { realizadas por pessoas aptas } \\
\text { Compreensões e opiniões: aquisição da compreensão de que o processo contábil é relevante para o } \\
\text { desempenho do negócio }\end{array}$ \\
\hline E8 & $\begin{array}{l}\text { Conhecimentos técnico-gerenciais: aquisição de conhecimentos sobre análise de mercado e } \\
\text { validação da ideia de produto } \\
\text { Compreensões e opiniões: aquisição da compreensão de que a busca e troca de informações são } \\
\text { processos importantes ao desenvolvimento do negócio }\end{array}$ \\
\hline E9 & $\begin{array}{l}\text { Compreensões e opiniões: aquisição da compreensão de que suas habilidades não contemplam todas } \\
\text { as necessidades da empresa }\end{array}$ \\
\hline
\end{tabular}

Fonte: elaboração própria.

Com base na análise e discussão dos resultados, na Figura 1, faz-se o delineamento do processo de aprendizagem a partir do erro vivenciado pelos sujeitos da pesquisa. Este processo tem início com a ocorrência de um erro, o qual, contudo, não foi imediatamente detectado, pois, antes disso, exceto pelo caso de um sujeito (E4), o erro manifestou-se de forma latente em situações-problema (de ordem técnico-operacional, gerencial, estratégica e comportamental) que emergiram durante a execução de uma atividade ou de um processo de trabalho. 
Figura 1 - Processo de aprendizagem individual a partir do erro, vivenciado pelos sujeitos da pesquisa

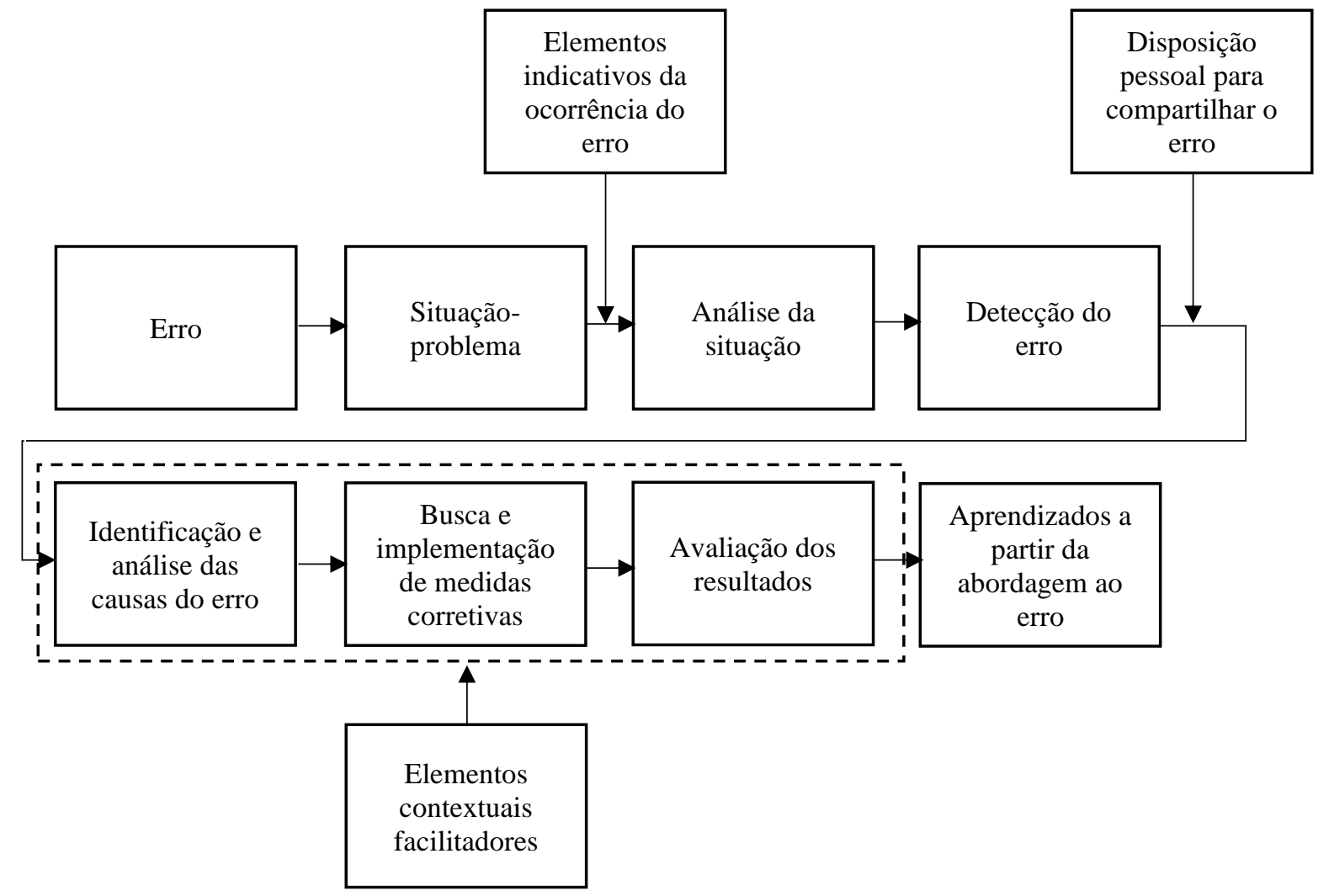

Fonte: elaboração própria.

Na sequência, mediante a influência de elementos indicativos da existência de um erro, como o feedback de outras pessoas e resultados de indicadores de desempenho, sucedeu-se um período de reflexão, e de busca e análise de informações atinentes à situação-problema, após o qual foi feita a efetiva detecção do erro. Observa-se que concomitantemente à avaliação da situação-problema os gestores compartilharam a ocorrência do erro com outros membros da organização, como sócios e membros das equipes de trabalho. Esta disposição pessoal para compartilhar o erro colaborou para que os mesmos se envolvessem no estágio de correção do erro, que, formalmente, teve início com a identificação e análise das causas do erro, seguidas da busca e implementação de medidas corretivas, e, então, a avaliação dos resultados.

Ainda em relação ao estágio de correção do erro, nota-se que a sua consecução foi facilitada por alguns elementos do contexto de ação dos sujeitos, como trocas de ideias junto a pessoas internas e externas à organização, e a orientação de especialistas (mentores de negócios). O processo culmina, então, com a consolidação ou reconhecimento das aprendizagens adquiridas no decorrer da abordagem à situação de erro

Por último, não se pretende sugerir que a aprendizagem a partir de um determinado erro finda-se, necessariamente, após a implementação das medidas corretivas do erro, uma vez que 
uma das formas mais comuns de aprendizagem é por assimilação, ou seja, “[...] o novo elemento é ligado como uma adição a um esquema ou padrão que já estava estabelecido" (ILLERIS, 2013, p. 22). Com isto, o aprendizado mais imediato à situação de erro pode proporcionar ou desdobrar-se em novas aprendizagens, em outras situações e contextos de ação do indivíduo.

\section{CONSIDERAÇÕES FINAIS}

Por meio desta pesquisa, buscou-se responder à questão sobre como se aborda o erro individual no ambiente de trabalho e sobre a forma como ele conduz a aprendizagens. A base para a resposta foi o entendimento segundo o qual a aprendizagem a partir do erro decorre da forma como é tratado o erro cometido. Contudo, para o adequado tratamento de um erro humano, depende-se da constatação de sua ocorrência, elemento do processo de aprendizagem a partir do erro que ganhou relevância nos achados da pesquisa.

Os resultados indicam que as situações-problema, por meio das quais os erros manifestam-se, constituem-se em um importante estágio para a detecção do erro, pois trazem consigo elementos indicativos da ocorrência de um erro, na forma de feedbacks de outras pessoas, indicadores de desempenho, pareceres e opiniões de especialistas, e conflitos interpessoais. Na literatura sobre o tema, no campo da aprendizagem nas organizações, não se observa o enfoque sobre tal aspecto, a despeito de sua relevância para a compreensão mais bem formulada sobre como a forma com que os problemas ocorridos no ambiente de trabalho são investigados - baseada na reflexão, e na busca e análise de informações - pode induzir a detecção de erros humanos. Pondera-se que tal achado representa uma contribuição teórica advinda do presente estudo.

Com base nos dados da pesquisa, a abordagem aos erros cometidos pelos gestores - ou seja, o modo pelo qual o erro foi tratado, a partir de sua identificação - mostrou-se consoante as etapas gerais da detecção, indicação (ou comunicação) e correção do erro, conforme descrito por Sasou e Reason (1999) e Zhao e Olivera (2006). Não obstante, identificaram-se elementos específicos do processo de abordagem ao erro nas empresas de base tecnológica, relativos às causas dos erros (preponderantemente, elementos cognitivos) e relacionados aos elementos contextuais que facilitaram o tratamento dos erros. Estes últimos, em essência, representam as atividades de aprendizagem informais e formais que concorreram, de modo mais explícito, para a formação de aprendizagens, pelos sujeitos. Com isso, evidenciou-se, como sugerido pela 
literatura, que o envolvimento do indivíduo no processo de detecção e correção do erro é a maneira pela qual o processo de aprendizagem individual a partir do erro torna-se possível.

Os resultados desta pesquisa trazem como contribuição adicional o delineamento de um percurso processual para a aprendizagem individual a partir do erro, no contexto de trabalho de gestores de empresas de base tecnológica, por meio do qual é possível evidenciar como os estágios da abordagem de detecção e correção do erro articulam-se com elementos que influenciam positivamente a aprendizagem a partir do erro. Tal perspectiva implica em que as abordagens ao fenômeno, inclusive nas organizações, devem levar em conta que a efetividade da aprendizagem a partir dos erros é dependente da forma pela a abordagem à situação de erro é realizada e em que medida as pessoas envolvem-se com ela.

Como principais limitações da pesquisa, elenca-se, primeiro, a investigação do fenômeno do erro individual ter sido, apenas, com base em uma fonte, qual a seja a visão dos gestores de empresas de base tecnológica; em segundo lugar, destacam-se as restrições decorrentes da coleta de dados qualitativos, em especial, a possibilidade de omissão de informações e de distorção de fatos, tanto por deliberação do sujeito quanto por esquecimento.

Para estudos futuros, sugere-se o desenvolvimento de investigações que ampliem o campo da pesquisa para empresas de base tradicional, ou seja, que não estejam baseadas no uso intensivo de novas tecnologias em suas operações e, assim, contrastar os processos de aprendizagem a partir do erro de grupos distintos de organizações. Também, recomendam-se pesquisas que se voltem à análise dos impactos, na aprendizagem a partir dos erros, das crenças e opiniões que os praticantes têm sobre o erro no ambiente de trabalho, bem como investigações que expandam a compreensão sobre o papel desempenhado pelas emoções negativas, no processo de aprendizagem a partir dos erros.

\section{REFERÊNCIAS}

BAUER, J.; MULDER, R. H. Modelling learning from errors in daily work. Learning in Health and Social Care, v. 6, p. 121-133, 2007, <http://dx.doi.org/10.1111/j.14736861.2007.00150.x>.

BAUER, M. W. Análise de conteúdo clássica: uma revisão. In: BAUER, M. W.; GASKELL, G. (Ed.). Pesquisa qualitativa com texto, imagem e som: um manual prático. Petrópolis: Vozes, 2002.

BAUDOUIN, J. M. A competência e a questão da atividade: rumo a uma nova conceituação didática da formação. In: DILZ, J.; OLLAGNIER, E. (Org.). O enigma da competência em educação. Porto Alegre: Artmed, 2004. 
CANNON, M. D.; EDMONDSON, A. C. Confronting failure: antecedents and consequences of shared beliefs about failure in organizational work groups. J. Organiz. Behav., v. 22, p. 161$177,2001$.

CRESWELL, J. W. Investigação qualitativa e projeto de pesquisa: escolhendo entre cinco abordagens. 3. ed. Porto Alegre: Penso, 2014.

DAHLIN, K. B.; CHUANG, Y. T.; ROULET, T. J. Opportunity, motivation and ability to learn from failures and errors: Review, synthesis, and the way forward. Academy of Management Annals, v. 12, n. 1, p. 252-277, 2017, <http://dx.doi.org/10.5465/annals.2016.0049>.

EDMONDSON, A. C. Learning from mistakes is easier said than done: group and organizational influences on the detection and correction of human error. Journal of Applied Behavioral Science, v. 32, p. 5-32, 1996.

FRESE, M.; KEITH, N. Action errors, error management and learning in organizations. Annual Review of Psychology, v, 66, p. 661-687, 2015, <http://dx.doi.org/10.1146/annurevpsych-010814-015205>.

GASKELL, G. Entrevistas individuais e grupais. In: BAUER, M. W.; GASKELL, G. (Ed.), Pesquisa qualitativa com texto, imagem e som: um manual prático. Petrópolis: Vozes, 2002.

GHARAIBEH, H. Project Team Learning, The Mystery Revealed. Journal of Organizational Learning \& Leadership, v. 10, n. 2, p. 1-15, 2012.

GOODMAN, P. S.; RAMANUJAM, R.; CARROLL, J. S.; EDMONDSON, A. C.; HOFMANN, D. A.; SUTCLIFFE, K. M. Organizational errors: Directions for future research. Research in Organizational Behavior, v. 31, p. 151-176, 2011, <http://dx.doi.org/10.1016/j.riob.2011.09.003>.

HARTEIS, C.; BAUER, B.; GRUBER, H. The culture of learning from mistakes: How employees handle mistakes in everyday work. International Journal of Educational Research, v. 47, p. 223-231, 2008, <http://dx.doi.org/10.1016/j.ijer.2008.07.003

HOMSMA, G. J.; VAN DYCK, C.; DE GILDER, D.; KOOPMAN. P. L.; ELFRING. T. Learning from error: the influence of error incident characteristics. J. Bus. Res., v. 62, p. 115122, 2009, <http://dx.doi.org/10.1016/j.jbusres.2007.12.003>.

ILLERIS, K. Uma compreensão abrangente sobre a aprendizagem humana. In: ILLERIS, K. (Org.). Teorias contemporâneas da aprendizagem. Porto Alegre: Penso, 2013.

KC, D.; STAATS, B. R.; GINO, F. Learning from My Success and from Others' Failure: Evidence from Minimally Invasive Cardiac Surgery. Management Science, v. 59, n. 11, p. 2435-2449, 2013, <http://dx.doi.org/10.1287/mnsc.2013.1720>.

KOLB, D. Experiential learning. Englewood Cliffs: Prentice-Hall, 1984.

LEFRANÇOIS, G. R. Theories of human learning: what the professor said. Belmont: Cengage Learning, 2012. 
LEI, Z., NAVEH, E.; NOVIKOV, Z. Errors in Organizations An Integrative Review via Level of Analysis, Temporal Dynamism, and Priority Lenses. Journal of Management, v. 42, n. 5 , p. 1315-1343, 2016, <http://dx.doi.org/10.1177/0149206316633745>.

LOCKETT, A.; WRIGHT, M. Resources, capabilities, risk capital and the creation of university spin-out companies. Research Policy, v. 4, n. 7, p. 1043-1057, 2005, <http://dx.doi.org/10.1016/j.respol.2005.05.006>.

LOVE, P. E. D.; JOSEPHSON, P. E. Role of error-recovery process in projects. Journal of Management in Engineering, v. 20, n. 2, p. 70-79, 2004.

MERRIAM, S. Qualitative research: a guide to design and implementation. San Francisco: Jossey-Bass, 2009.

OHLSSON, S. Learning from performance errors. Psychological Review, v. 103, n. 2, p. 241262, 1996.

PERUSSI FILHO, S.; ESCRIVÃO FILHO, E.. Processo de criação de estratégia em pequenas empresas de base tecnológicas. Gestão \& Produção, v. 19, n. 1, p. 173-188, 2012, <http://dx.doi.org/10.1590/S0104-530X2012000100012>.

PUTZ, D.; SCHILLING, J.; KLUGE, A.; STANGENBERG, C. Measuring organizational learning from errors. Management Learning, v. 44, n. 5, p. 511-536, 2013, <http://dx.doi.org/10.1177/1350507612444391>.

REASON, J. Human Error. Cambridge: University Press, 1990.

RYBOWIAK, V.; GARST, H.; FRESE, M.; BATINIC, B. Error Orientation questionnaire (E. O. Q.): Reliability, validity, and different language equivalence. Journal of Organizational Behavior, v. 20, p. 527-547, 1999.

SASOU, K.; REASON, J. Team errors: Definitions and taxonomy. Reliability Eng. Sys. Safety, v. 65, p. 1-9, 1999.

SEBRAE - SERVIÇO BRASILEIRO DE APOIO ÀS MICRO- E PEQUENAS EMPRESAS. Sobrevivência das empresas no Brasil. Brasília: Autores, 2016.

TJOSVOLD, D.; YU, Z. Y.; HUI, C. Team learning from mistakes: The contribution of cooperative goals and problem-solving. Journal of Management Studies, v. 41, n. 7, p. 1223 1245, 2004.

VAN DER LINDEN, D.; SONNENTAG, S.; FRESE, M.; VAN DYCK, C. Exploration strategies, performance, and error consequences when learning a complex computer task. Behaviour \& Information Technology, v. 20, n. 3, p. 189-198, 2001.

VAN DYCK, C.; FRESE, M.; BAER, M.; SONNENTAG, S. Organizational Error Management Culture and Its Impact on Performance: A Two-Study Replication. Journal of Applied Psychology, v. 90, n. 6, p. 1228-1240, 2005, <http://dx.doi.org/10.1037/00219010.90.6. 1228>. 
ZHAO, B. Learning from errors: The role of context, emotion, and personality. Journal of Organizational Behavior, v. 32, n. 3, p. 435-463, 2011.

ZHAO, B.; OLIVERA, F. Error reporting in organizations. Academy of Management Review, v. 31, p. 1012-1030, 2006. 